\title{
Altered Lung Development after Prenatal Nicotine Exposure in Young Lambs
}

\author{
KENNETH SANDBERG, STANLEY D. POOLE, ASHRAF HAMDAN, PATRICK ARBOGAST, AND \\ HÅKAN W. SUNDELL
}

\author{
Department of Pediatrics [H.W.S., S.D.P., A.H.], Department of Preventive Medicine [P.A.], Vanderbilt \\ University School of Medicine, Nashville, Tennessee 37232, U.S.A., and Department of Women and Child \\ Health [K.S.], Göteborg University, S-416 85 Göteborg, Sweden
}

\begin{abstract}
There is compelling evidence that prenatal nicotine exposure permanently alters lung development and airway function. The aim of this study was to determine how prenatal nicotine exposure alters proximal and distal airway function. Thirteen lambs were continuously exposed during the last fetal trimester to low-dose nicotine (LN) and 12 to a moderate dose (MN) (maternal s.c. dose: 0.5 and $1.5 \mathrm{mg} / \mathrm{kg} / \mathrm{d}$, respectively). Ten lambs served as controls (C). Proximal airway function was measured by lung mechanics. A multiple-breath $\mathrm{N}_{2}$ washout technique was used to measure lung volume (functional residual capacity) and efficiency of gas mixing in distal airways, i.e. terminal respiratory units (moment ratio and nitrogen clearance). In comparison with $\mathrm{C}$, both $\mathrm{LN}$ and $\mathrm{MN}$ had significantly reduced specific airway conductance to the same extent at a median study age of 12,25 , and $51 \mathrm{~d}$, indicating signs of proximal airway obstruction. Distal airway function showed significant improvement in LN. Ventilation and functional residual capacity were unaffected. In summary, prenatal nicotine exposure induced airway obstruction in proximal airways and improved gas mixing in distal airways, possibly reflecting restriction in proximal airway growth and
\end{abstract}

ABSTRACT

accelerated maturation of the acinar part of the lung, respectively. We speculate that prenatal nicotine exposure has a disparate impact on airway development and function. The effect on the distal airways seemed to be inversely related to dose, which was not the case in the large airways. The altered airway function persisted during the study period, indicating that the effects of prenatal nicotine exposure might be permanent. (Pediatr Res 56: 432-439, 2004)

$\mathbf{C}$, control
$\mathbf{M}_{\mathbf{0}}$, zero moment
$\mathbf{C}_{\mathbf{d y n}}$, dynamic lung compliance
$\mathbf{M}_{\mathbf{1}}$, first moment
$\mathbf{F R C}$, functional residual capacity
$\mathbf{N C}$, nitrogen clearance
$\mathbf{L N}$, low-dose nicotine
$\mathbf{R}_{\mathbf{l}}$, lung resistance
$\mathbf{M N}$, moderate-dose nicotine

Environmental tobacco smoke is a severe health problem, not only for the whole pediatric population but also for the fetus in utero (1). There is compelling evidence that maternal smoking is associated with premature birth, low birth weight, and increased fetal and neonatal morbidity as well as mortality $(2,3)$. Epidemiologic studies have shown that environmental tobacco smoke is associated with a significantly increased incidence of wheezing, bronchitis, lower respiratory illness, and increased number of hospital admissions during infancy and childhood $(4,5)$. These

Received October 1, 2003; accepted April 22, 2004.

Correspondence: Håkan W. Sundell, M.D., Professor of Pediatrics, Vanderbilt University School of Medicine, A-0126, MCN, Nashville, TN 37232-2585, U.S.A.; e-mail: hakan.sundell@vanderbilt.edu

Supported by grants from the Smokeless Tobacco Research Council (\#0765). K.S. was in part supported by The Research Fund at the Queen Silvia Children's Hospital, Göteborg, Sweden.

These results were presented in part at the annual meeting of the American Pediatric Society and Society for Pediatric Research 2002.

DOI: 10.1203/01.PDR.0000136276.52104.61 studies further suggest that there is a stronger correlation between prenatal, rather than postnatal, exposure and lower respiratory illness in the offspring of smoking mothers.

Altered mechanical properties of the lungs have also been found in these infants and children (6-12). These abnormalities in lung function are dominated by signs of airway obstruction with reduced forced expiratory flow rates at FRC, increased airway resistance, and a decrease in the ratio of time to peak tidal expiratory flow to total expiratory time (Tptef/Te). Low FRC and decreased lung compliance have also been found in infants exposed to environmental tobacco smoke. Studies of sudden infant death victims have shown that infants of mothers who smoked during pregnancy have abnormal airway pathology in the form of greater inner airway wall thickness and higher proportions of airway smooth muscle compared with infants of mothers who did not smoke $(13,14)$.

The relationship between prenatal nicotine exposure and altered lung development and function has been studied in 
several animal models (15-19). These studies have shown altered alveolar structure and lung hypoplasia, as well as changes in the airways, such as increased wall dimensions and increased collagen deposition. Decreased expiratory flow rates and increased pulmonary resistance have also been found in these animal studies.

Apart from the detrimental effects of prenatal nicotine exposure on lung development and function, it is known that premature infants of smoking mothers have a decreased risk to develop neonatal respiratory distress syndrome (20-22). These paradoxical findings have been attributed to an enhancement of lung maturation as evidenced by a more mature lecithin/ sphingomyelin ratio in amniotic fluid from smoking compared with nonsmoking mothers. In addition, it has been shown that nicotine stimulates branching morphogenesis and surfactant gene expression in embryonic mouse lung culture (23). It has been demonstrated in rhesus monkeys that prenatal nicotine exposure increases the relative number of type 2 cells in developing alveoli and alveolar ducts, as defined by increased expression of type 2 cell SP-B mRNA together with increased levels of SP-B in amniotic fluid (16). As an explanation for the apparent differences in nicotinic effects on proximal compared with distal airways, it has been proposed that prenatal nicotine exposure exerts an anatomically dysanaptic effect on the development of the fetal lung, meaning that two components of an organ grow disconcordantly (17). In the case of the nicotineexposed fetal lung, this could result in inhibition of proximal airway growth and simultaneous stimulation of the alveolar part of the lung.

The aim of this study was to determine the effects of a moderate- and a low-dose prenatal nicotine exposure on both proximal and distal (terminal respiratory units) airway function in young lambs during the first 2 mo of life.

\section{METHODS}

Subjects. Thirty-five term lambs of mixed breed delivered by spontaneous vaginal delivery were studied three times during their first 2 mo of life. Twenty-five of these lambs were exposed to nicotine prenatally, 13 with a low dose (LN), and 12 with a moderate dose $(\mathrm{MN})$. Ten lambs served as control animals $(\mathrm{C})$. An adaptive randomization procedure was used to randomly allocate ewes to the three study groups (24). The study was blinded and the investigators were unaware of the grouping of the lambs until the study was completed.

There were no major differences in birth weight or gestational age between the groups. The lambs were studied at the median (range) ages of 12 (5-17), 25 (22-34), and 51 (45-61) $\mathrm{d}$, i.e. the earliest possible time after postoperative recovery, as late as practical with this chronic preparation, and once in between. [Median (range) study ages for each group were 12 (5-17), 26 (24-34), and 51 (45-61) d for LN lambs; 12 (7-16), 24 (22-27), and 51 (47-58) d for MN lambs; and 12 (8-13), 25 (23-28), and 52 (49-54) d for the control group.] The research protocol was approved by the Vanderbilt University Animal Care Committee.

Prenatal nicotine exposure. The fetal sheep were exposed to nicotine during the last third of gestation, when differenti- ation of the peripheral respiratory unit is very intense. This third trimester exposure minimizes the risk for fetal growth restriction and enables a comparison with previous studies of the breathing pattern in young lambs after prenatal nicotine exposure (25). Osmotic pumps (Alzet, Model 2ML4, DURECT Corp., Cupertino, CA, U.S.A.) were implanted subcutaneously in the ewe on approximately d 98 of the 147-d gestation. The pumps delivered nicotine bitartrate of approximately $0.5 \mathrm{mg} / \mathrm{kg} / \mathrm{d}$ in the LN group and $1.5 \mathrm{mg} / \mathrm{kg} / \mathrm{d}$ in the MN group. The LN dose was comparable to the dose we previously used (25) and results in nicotine levels obtained by light smokers $(<10$ cigarettes/d), whereas the $\mathrm{MN}$ dose corresponds to the dose obtained by moderate smokers (approximately 20 cigarettes/d) (26). The ewes of the control lambs received normal saline. The pumps were replaced after $28 \mathrm{~d}$ and removed after delivery of the lamb. Maternal plasma concentrations of nicotine and cotinine were determined by gas chromatography with nitrogen-phosphorus detection (27, 28) from samples obtained $14 \mathrm{~d}$ after the first implantation of the capsules, i.e. on approximately d 112 of gestation.

Instrumentation. The lambs were instrumented 3-7 d after delivery using anesthesia with Telazol (Fort Dodge Animal Health, Fort Dodge, IA 50501) (tiletamine $\mathrm{HCl}$ and zolazepam $\mathrm{HCl}$ ) followed by isoflurane. Polyvinyl chloride catheters were placed in a cranial tibial artery and a lateral saphenous vein. Two pleural balloons (Sil-Tec envelopes (Technical Products Inc. of Georgia, Decatur, GA 30035)) for measurements of pleural pressure were placed in the right pleural space through a small thoracotomy. A tracheostomy with placement of a tracheal window was also performed. When the lambs were not studied, tracheal patency was reestablished with a piece of endotracheal tube (Portex, Keene, NH, U.S.A.) (25). At least $48 \mathrm{~h}$ postoperative recovery was allowed before the first study. Antibiotics (gentamicin and ticarcillin) were given daily from the day of instrumentation until completion of the last study.

Lung function measurements and calculations. On each study occasion, the lamb was standing in a loose-fitting sling (Alice King Chatham Medical Arts, Hawthorne, CA, U.S.A.). The lambs were unanesthetized and unsedated during the first two studies. Because older unsedated lambs can be very restless during these studies, they were lightly sedated on the third study occasion with chloral hydrate using a $50 \mathrm{mg} / \mathrm{kg}$ bolus injection followed by an infusion of $25 \mathrm{mg} / \mathrm{kg} / \mathrm{h}$. Measurements before and after sedation did not reveal any significant effect on lung function (data not presented). The lambs were breathing air spontaneously and the studies were performed during quiet breathing while awake. The technique for measurements and calculations of lung function used in this study has been evaluated previously and described in detail both in lambs (29) and in newborn infants (30). Lung mechanics, ventilation, FRC, and indices of gas mixing efficiency in distal airways were assessed.

Ventilation flow in the cuffed endotracheal tube inserted through the tracheostomy was measured by a heated pneumotachograph (model 3700, Hans Rudolph Inc., Kansas City, MO, U.S.A.) connected to a Sensortechnics pressure transducer (model 103LP, Sensortechnics GmbH, Puchheim, Germany) and a carrier demodulator. Flow was integrated to volume. Transpulmonary pressure was measured between the 
Table 1. Lung function testing results

\begin{tabular}{|c|c|c|c|c|c|c|}
\hline \multirow[b]{2}{*}{ Study groups } & \multicolumn{3}{|c|}{ Postnatal age $12 \mathrm{~d}$} & \multicolumn{3}{|c|}{ Postnatal age $25 \mathrm{~d}$} \\
\hline & $\mathrm{LN}$ & MN & $\mathrm{C}$ & $\mathrm{LN}$ & $\mathrm{MN}$ & $\mathrm{C}$ \\
\hline Number of lambs & 13 & 12 & 10 & 13 & 12 & 10 \\
\hline $\mathrm{FRC}, \mathrm{mL} \cdot \mathrm{kg}^{-1}$ & $35 \pm 6.6$ & $32 \pm 5.0$ & $34 \pm 4.2$ & $31 \pm 6.6$ & $29 \pm 5.4$ & $30 \pm 5.6$ \\
\hline Compliance, $\mathrm{mL} \cdot \mathrm{cm} \mathrm{H}_{2} \mathrm{O}^{-1}$ & $14.8 \pm 5.3$ & $13.4 \pm 5.3$ & $16.1 \pm 7.4$ & $16.2 \pm 3.8$ & $19.5 \pm 8.3$ & $15.9 \pm 4.0$ \\
\hline Specific compliance, $\mathrm{cm} \mathrm{H}_{2} \mathrm{O}^{-1}$ & $0.054 \pm 0.01$ & $0.053 \pm 0.01$ & $0.055 \pm 0.02$ & $0.045 \pm 0.02$ & $0.054 \pm 0.02$ & $0.046 \pm 0.01$ \\
\hline Resistance, $\mathrm{cm} \mathrm{H}_{2} \mathrm{O} \cdot \mathrm{L}^{-1} \cdot \mathrm{s}$ & $11.0 \pm 4.2$ & $10.7 \pm 4.4$ & $7.2 \pm 4.1$ & $10.1 \pm 6.7$ & $9.9 \pm 3.6$ & $8.4 \pm 3.7$ \\
\hline Moment ratio, $\mathrm{M}_{1} / \mathrm{M}_{0} * *$ & $2.55 \pm 0.2$ & $2.87 \pm 0.5$ & $2.70 \pm 0.2$ & $2.40 \pm 0.2$ & $2.61 \pm 0.3$ & $2.70 \pm 0.3$ \\
\hline Nitrogen Clearance Index $* *$ & $7.2 \pm 1.2$ & $9.3 \pm 3.1$ & $8.1 \pm 1.2$ & $6.8 \pm 0.7$ & $8.4 \pm 1.5$ & $8.5 \pm 1.8$ \\
\hline Tidal volume, $\mathrm{mL} \cdot \mathrm{kg}^{-1}$ & $9.5 \pm 1.2$ & $8.8 \pm 1.0$ & $9.0 \pm 1.4$ & $8.0 \pm 1.3$ & $7.7 \pm 1.1$ & $7.9 \pm 1.5$ \\
\hline Breathing frequency, $\min ^{-1}$ & $47 \pm 13$ & $56 \pm 13$ & $48 \pm 9.9$ & $39 \pm 13$ & $38 \pm 8.1$ & $37 \pm 8.8$ \\
\hline Minute ventilation, $\mathrm{mL} \cdot \mathrm{kg}^{-1} \cdot \mathrm{min}^{-1}$ & $435 \pm 75$ & $493 \pm 184$ & $425 \pm 78$ & $297 \pm 63$ & $292 \pm 59$ & $296 \pm 45$ \\
\hline
\end{tabular}

Values are mean $\pm \mathrm{SD}$.

$\ddagger$ MN different from $\mathrm{C}$ at $p<0.01$ over the whole study period.

* LN different from $\mathrm{C}$ at $p<0.05$ over the whole study period.

** LN different from $\mathrm{C}$ at $p<0.01$ over the whole study period.

airway (measured at the end of a 15-gauge blunt needle inserted perpendicularly and located in the center of the endotracheal tube connector) and the pleural balloon (Sil-Tec envelope) in the right pleural space by a pressure transducer (Sensortechnics model 140PC) and a carrier demodulator. Nitrogen concentration in the breathing gas was measured continuously. The probe of the nitrogen analyzer (Model 505, Med Science, Division of Advanced Instruments, Inc., St. Louis, MO 63152) was mounted at the outlet of the endotracheal tube, which was connected to a system of tubing with a continuous bypass flow of breathing gas. A nitrogen washout test was performed by changing breathing gas instantaneously to $100 \%$ oxygen during an expiration. The nitrogen washout test lasted until $1 / 40^{\text {th }}$ of the end-tidal nitrogen concentration before the start of $100 \%$ oxygen breathing was reached. The washout test was performed two to three times in each lamb with at least $5 \mathrm{~min}$ in between to allow gas equilibration within the lung (31).

Before the study, the equipment measuring lung mechanics was tested for its frequency response up to $20 \mathrm{~Hz}$. No deviations in phase or amplitude were noted, and the pneumotachometer was linear for the actual flow range.

All signals were digitized with 12-bit accuracy at a frequency of $250 \mathrm{~Hz}$ and stored to a disc. For the analysis, the time scale of the nitrogen signal was corrected for the measured transit time to the meter.

Lung mechanics were calculated from sampled ventilation flow and transpulmonary pressure. Assuming a singlecompartment lung model, $\mathrm{C}_{\mathrm{dyn}}$ and $\mathrm{R}_{1}$ were determined from the equation of motion by means of multiple linear regression analysis. Specific compliance was calculated as $\mathrm{C}_{\mathrm{dyn}} / \mathrm{FRC}$ and specific conductance as $1 / \mathrm{R}_{\mathrm{I}} / \mathrm{FRC}$. The methods for lung mechanics calculations have been described previously (32).

The total exhaled $\mathrm{N}_{2}$ volume was calculated as the sum of the $\mathrm{N}_{2}$ volumes exhaled in each breath during the $\mathrm{N}_{2}$ washout test. This volume was obtained by summing the product of simultaneously measured flow and $\mathrm{N}_{2}$ concentration signals. No correction was made for tissue derived nitrogen. FRC was calculated as the total expired nitrogen volume during wash- out, divided by end-tidal nitrogen concentration preceding the washout.

Efficiency of gas mixing was assessed by calculating the nitrogen clearance (NC) index and moment ratio from the course of nitrogen elimination (33). NC index was defined as the ventilation volume necessary to dilute the nitrogen lung volume from 90 to $10 \%$ of its total value, divided by FRC. The zero $\left(\mathrm{M}_{0}\right)$ and first $\left(\mathrm{M}_{1}\right)$ moments of end-tidal nitrogen concentration, with accumulated expired volume normalized by FRC as the independent variable, were calculated and the ratio of $\left(\mathrm{M}_{1} / \mathrm{M}_{0}\right)$ was determined as previously described (31). Tidal volume, breathing frequency, and minute ventilation were calculated from the recording of ventilatory flow.

Statistics. Data are reported at each time period as mean \pm SD except in the figures where data are presented as mean \pm SEM. Since each lamb was studied three times over the study period during their first $2 \mathrm{mo}$ of life, response features analyses were performed. For each lamb, the area-under-the-curve (AUC) was computed for each outcome (34). In addition, rate-of-change over time was estimated for each lamb and each outcome using linear regression. One-way ANOVA was used to compare mean AUC and rate-of-change across the three groups, and two-sample $t$ tests were used to compare the LN and $\mathrm{MN}$ groups to the control group. If normality of these response features was suspect, the Kruskal-Wallis and MannWhitney $U$ tests were used. A $p$ value $<0.05$ was regarded as statistically significant.

\section{RESULTS}

Nicotine levels. Maternal plasma concentrations for nicotine and the major nicotine metabolite, cotinine, were $5.8 \pm 2.8$ and $16.8 \pm 5.1 \mathrm{ng} / \mathrm{mL}$ for $\mathrm{LN}$ and $19.8 \pm 2.3$ and $70.9 \pm 25.4$ $\mathrm{ng} / \mathrm{mL}$ for $\mathrm{MN}$, respectively.

Body weight. There were no significant differences in weights of the lambs between the groups on any study occasion, and there were no differences in postnatal weight gain (Table 1). 
Table 1. (Continued)

\begin{tabular}{|c|c|c|c|}
\hline \multirow[b]{2}{*}{ Study groups } & \multicolumn{3}{|c|}{ Postnatal age $51 \mathrm{~d}$} \\
\hline & $\mathrm{LN}$ & $\mathrm{MN}$ & $\mathrm{C}$ \\
\hline Number of lambs & 13 & 12 & 10 \\
\hline $\mathrm{FRC}, \mathrm{mL} \cdot \mathrm{kg}^{-1}$ & $29 \pm 5.6$ & $28 \pm 4.2$ & $26 \pm 7.7$ \\
\hline Compliance, $\mathrm{mL} \cdot \mathrm{cm} \mathrm{H}_{2} \mathrm{O}^{-1}$ & $27.1 \pm 8.6$ & $21.9 \pm 9.4$ & $25.9 \pm 8.2$ \\
\hline Specific compliance, $\mathrm{cm} \mathrm{H}_{2} \mathrm{O}^{-1}$ & $0.049 \pm 0.02$ & $0.042 \pm 0.01$ & $0.054 \pm 0.02$ \\
\hline Moment ratio, $\mathrm{M}_{1} / \mathrm{M}_{0}^{* *}$ & $2.26 \pm 0.1$ & $2.22 \pm 0.3$ & $2.45 \pm 0.4$ \\
\hline Nitrogen Clearance Index $* *$ & $6.4 \pm 1.1$ & $6.6 \pm 1.2$ & $6.8 \pm 2.4$ \\
\hline Tidal volume, $\mathrm{mL} \cdot \mathrm{kg}^{-1}$ & $7.7 \pm 1.6$ & $7.0 \pm 0.7$ & $7.5 \pm 1.7$ \\
\hline Breathing frequency, $\min ^{-1}$ & $28 \pm 2.9$ & $27 \pm 4.0$ & $28 \pm 5.8$ \\
\hline Minute ventilation, $\mathrm{mL} \cdot \mathrm{kg}^{-1} \cdot \mathrm{min}^{-1}$ & $216 \pm 44$ & $187 \pm 29$ & $206 \pm 43$ \\
\hline
\end{tabular}

Lung volume. The increase in $\mathrm{FRC}$ during the study period (the studies at 12, 25, and $51 \mathrm{~d}$ ) differed between the groups. Compared with the control lambs, the gain in FRC in the LN lambs was $7.0 \pm 1.8 \mathrm{~mL} / \mathrm{d}$, whereas the corresponding FRC gain in the $\mathrm{C}$ lambs was $4.5 \pm 2.0 \mathrm{~mL} / \mathrm{d}(p<0.01)$. The corresponding value for the MN lambs was $6.4 \pm 2.4 \mathrm{~mL} / \mathrm{d}$, which also differed from the $\mathrm{C}$ lambs $(p<0.05)$. The difference in FRC between LN and C lambs was confirmed by a significant difference in mean regression slope over time in FRC (FRC change per day) between these groups $(p<0.01)$. The corresponding slope difference between $\mathrm{MN}$ and $\mathrm{C}$ lambs was of borderline significance $(p=0.07)$.

Normalized to body weight, there were no significant differences in FRC/ $\mathrm{kg}$ between the study groups on any study occasion (Table 1).

Mechanical properties of the lungs. Results from lung mechanics measurements on all three study occasions are presented in Table 1. There was a similar increase over time in $\mathrm{C}_{\mathrm{dyn}}$ in all study groups, and there were no significant differences between the groups (Fig. $1 A$ ). $\mathrm{C}_{\mathrm{dyn}}$ normalized to lung volume (specific compliance, $\mathrm{C}_{\mathrm{dyn}} / \mathrm{FRC}$ ), did not differ between the groups during the whole study period, and there was no significant change over time in any of the nicotine or control groups (Fig. 1B).

Airway resistance was higher in the nicotine-exposed lambs compared with controls, although the difference was not statistically significant between the groups during the whole study period overall ( $p=0.06$ ) ( (Fig. $2 A)$. However, when airway resistance was normalized to lung volume (FRC), specific conductance $\left(1 / \mathrm{R}_{1} / \mathrm{FRC}\right)$ was statistically different between the groups during the whole study period overall $(p<0.01)$. Both the $\mathrm{LN}$ and the MN groups had significantly lower $1 / \mathrm{R}_{1} / \mathrm{FRC}$ when compared with the $\mathrm{C}$ group during the whole study period (LN versus $\mathrm{C}: p<0.05$ and $\mathrm{MN}$ versus $\mathrm{C}: p<0.01$ ) (Fig. 2B). The differences in specific conductance seemed to persist over time and the nicotine groups did not differ from each other.

Gas-mixing efficiency. Results of moment analysis and NC index are presented in Table 1. In the moment analysis, there was an overall statistically significant difference among the three groups during the whole study period $(p<0.05)$. The

\section{A Dynamic Lung Compliance}

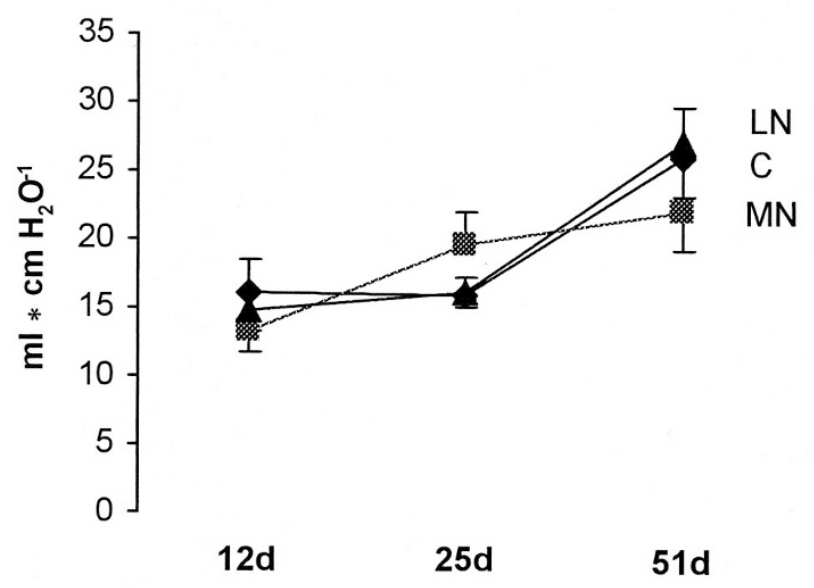

B Specific Compliance

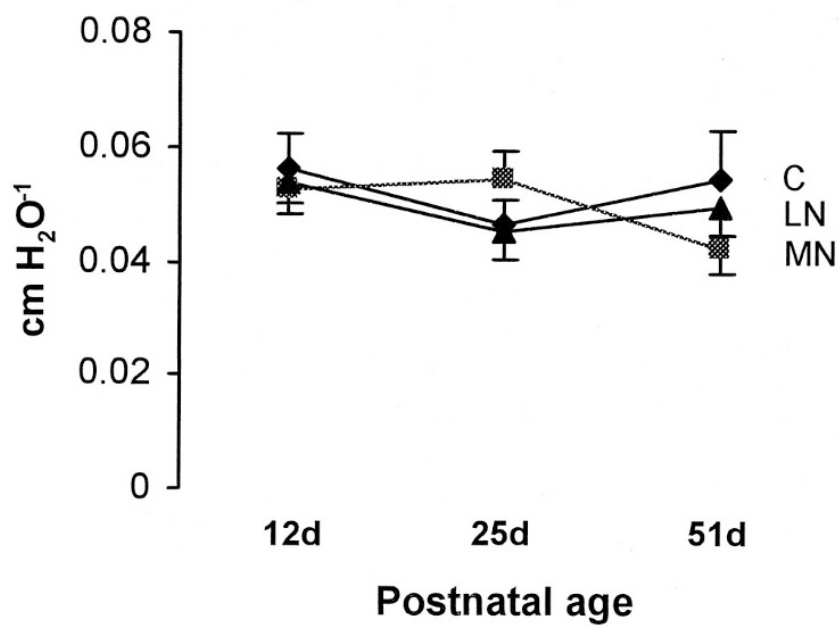

Figure 1. Dynamic lung compliance $(A)$ and specific compliance $(B)$ in 13 low-dose nicotine (LN, filled triangles), 12 moderate-dose nicotine (MN, filled squares), and 10 control (C, filled diamonds) lambs studied at a median age of 12,25 , and $51 \mathrm{~d}$. Values are mean \pm SEM. No statistically significant differences were found between the groups. 


\section{A Airway Resistance}

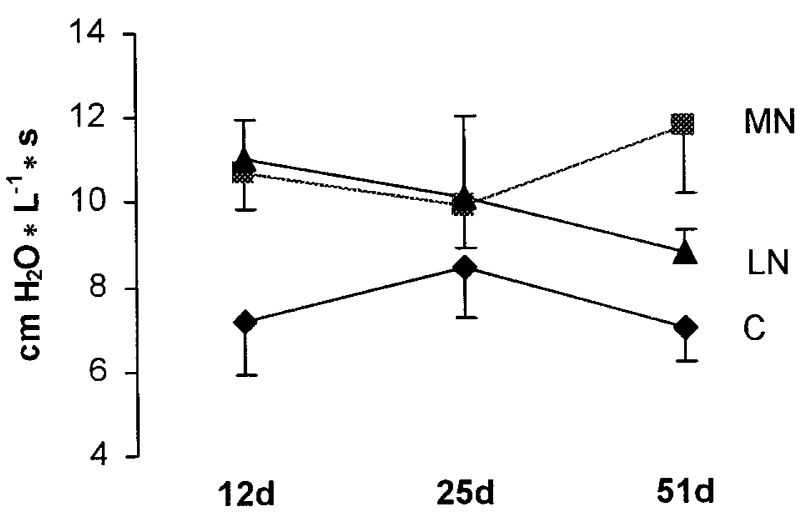

B Specific Conductance

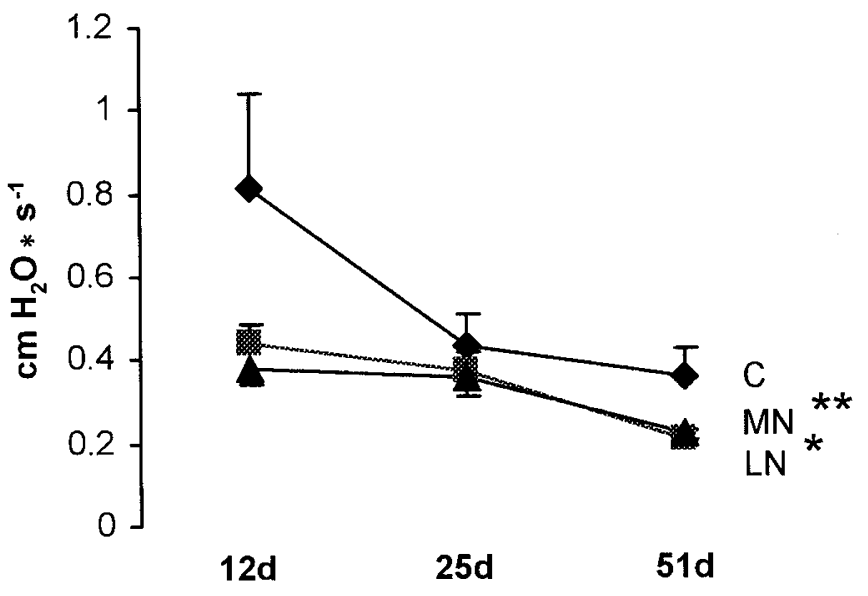

Postnatal age

Figure 2. Airway resistance $(A)$ and specific conductance $\left(1 / \mathrm{R}_{\mathrm{l}} / \mathrm{FRC}\right)(B)$ in 13 low-dose nicotine (LN, filled triangles), 12 moderate-dose nicotine (MN, filled squares), and 10 control (C, filled diamonds) lambs studied at a median age of 12, 25, and $51 \mathrm{~d}$. Values are mean \pm SEM. *Specific conductance was different from $\mathrm{C}$ over the study period at $p<0.01$. **Specific conductance was different from $\mathrm{C}$ over the study period at $p<0.01$.

$\mathrm{M}_{1} / \mathrm{M}_{0}$ ratio was significantly lower in the $\mathrm{LN}$ group when compared with controls during the whole study period $(p<$ 0.01) (Table 1 and Fig. 3). This difference means that gas mixing in the lungs was more efficient in the LN-exposed lambs compared with the controls. This difference seemed to persist over the study period. Moment ratio in the MN lambs, however, did not differ significantly from the controls when tested over time.

There was an overall statistically significant difference between the groups for the $\mathrm{NC}$ index during the study period ( $p<$ $0.01)$. The LN lambs compared with the controls showed a significantly lower NC index (improved gas mixing) during the whole study period $(p<0.01)$, whereas the MN lambs did not differ significantly from the control lambs (Fig. 4).

Ventilation. Respiratory rate as well as tidal volume and minute ventilation, normalized to body weight, were higher on the first study occasion compared with the second and third

\section{Moment Analysis}

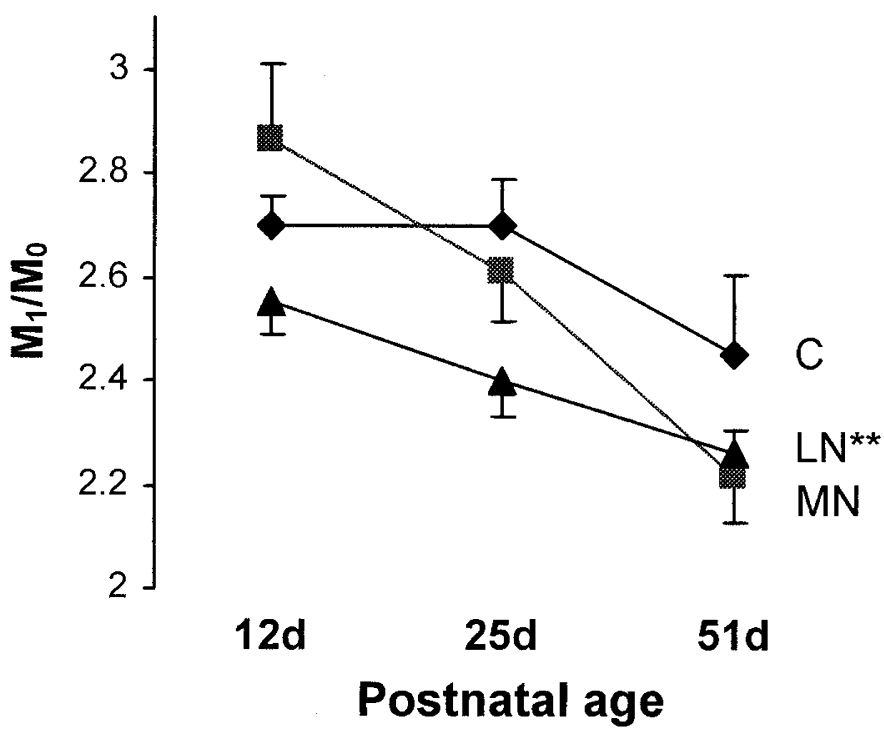

Figure 3. Moment analysis in 13 low-dose nicotine (LN, filled triangles), 12 moderate-dose nicotine (MN, filled squares), and 10 control (C, filled diamonds) lambs studied at a median age of 12,25 , and $51 \mathrm{~d}$. Values are mean \pm SEM. **Different from $\mathrm{C}$ over the study period at $p<0.01$.

\section{Nitrogen Clearance Index}

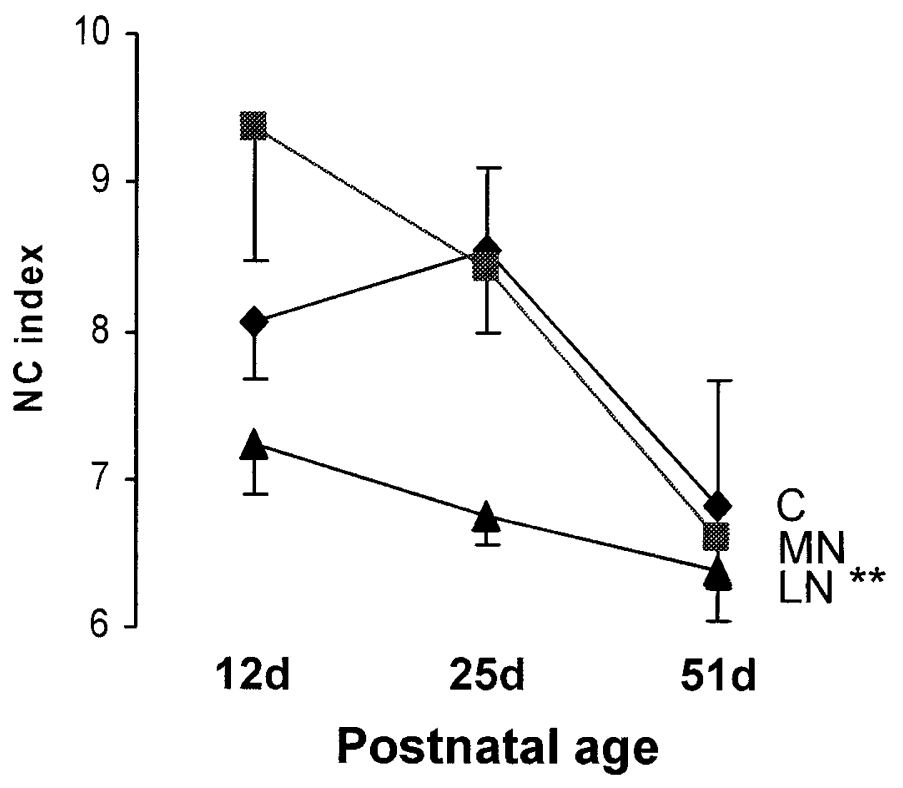

Figure 4. Nitrogen clearance index in 13 low-dose nicotine (LN, filled triangles), 12 moderate-dose nicotine (MN, filled squares), and 10 control (C, filled diamonds) lambs studied at a median age of 12, 25, and $51 \mathrm{~d}$. Values are mean \pm SEM. **Different from $\mathrm{C}$ over the study period at $p<0.01$.

(Table 1). There were highly significant differences between the first and last study for respiratory rate, tidal volume, and minute ventilation in all three study groups $(p<0.01$ by paired $t$ test). There were no differences in ventilation between the study groups on any study occasion. Comparison of the rate of change in ventilation parameters using mean regression slopes for each study group showed no significant differences between the groups. 


\section{DISCUSSION}

This study in young lambs has demonstrated that continuous prenatal exposure to either a low or a moderate dose of nicotine during the third trimester induces reduced specific airway conductance, indicating an obstruction in the proximal airways. Indices of distal airway function (moment ratio and nitrogen clearance) were significantly lower after a low dose of prenatal nicotine exposure, indicating increased gas mixing efficiency. These results support the concept that nicotine might have a different impact on different parts of the airways. Disparity of the nicotinic effect on proximal versus distal airway development and function and persistence of these changes during the whole 7 -wk study period are the main results in our study that have not been reported by other investigators.

Proximal airway function. Measurement of airway resistance mainly reflects resistance to gas flow in proximal large airways $(35,36)$, where the gas flow is high due to a relatively narrow total cross-sectional area of the airways compared with the distal part of the lung. Factors limiting total cross-sectional area of the large airways alter the resistive part of the mechanical properties of the lung to a higher extent than airway changes in small peripheral airways, where gas flow is comparatively low due to larger total cross sectional airway diameter. Jones et al. (12) reported in a recent study that infants of mothers who smoked during pregnancy had reduced forced expiratory flow when examined by the rapid thoracic compression technique. This technique is assumed to measure flow resistance in the small airways between alveoli and the flow limiting segment (wherever the disease process is located) proximal to the alveoli (36). The forced expiratory flow technique also differs from the gas dilution technique used by us, which predominantly measures function of the most distal part of the airways (acinus with respiratory bronchioles) where the gas mixing takes place.

In the present study, measurements of lung mechanics showed a significant difference in airway conductance between nicotine-exposed lambs and controls. Specific conductance was significantly reduced to the same extent during the whole study period by both the low and the moderate nicotine dose. Although the maternal nicotine doses may appear high compared with human cigarette smokers, the achieved maternal plasma nicotine concentrations of the $\mathrm{LN}$ and $\mathrm{MN}$ group correspond to those observed in human smokers smoking $<10$ and approximately 20 cigarettes per day, respectively (26). Concentrations of cotinine, the major metabolite of nicotine that is thought to be pharmacologically inactive (37), were considerably lower than those observed in human smokers (26). These nicotine and cotinine concentrations mean that prenatal exposure to even a fairly low dose of nicotine affects proximal airway function with increased resistance to gas flow. The change in airway conductance prevailed during the whole study period, indicating a possible permanent alteration of the proximal airways.

Airway obstruction after prenatal nicotine exposure is in agreement with previous studies both in infants (6-12) and in rhesus monkeys (17). A possible explanation for this obstruction is provided by Sekhon et al. (16), who showed that prenatally administered nicotine increased $\alpha 7$ nicotine acetylcholine receptor subunit expression and binding in the fetal lung. They subsequently reported that $\alpha 7 \mathrm{nAChR}$ co-localized with collagen in the same airway wall cells, suggesting that nicotine directly interacted with $\alpha 7 \mathrm{nAChR}$ to increase collagen deposition and, therefore, airway wall dimensions in the fetal lung (19). In addition, increased airway smooth muscle may contribute to excessive airway narrowing, as has been found in intrauterine smoke-exposed infants who died from SIDS (14).

Decreased airway dimensions may also be a result of reduced forces opposing airway narrowing as a result of decreased alveolar attachment points, as demonstrated in human infants and neonatal guinea pigs exposed to cigarette smoke in utero $(18,38)$, but it is not known whether this would affect airway resistance.

The elasticity of the lung (compliance and specific compliance) seemed to have been unaffected in the present study. The unchanged compliance is consistent with the results in prenatally nicotine-exposed monkeys (17). In contrast, parenchymal elastic tissue was reduced after prenatal maternal smoke or nicotine exposure in rat pups $(15,39)$.

Distal airway function. Effects of prenatal nicotine exposure on the terminal respiratory unit (the acinus, including the alveolar space and respiratory bronchioles, where gas mixing takes place mainly by diffusion) have been contradictory. In the rat, nicotine induced severe damage to normal alveolar structure $(39,40)$, whereas improvement of the surfactant system has been reported in the rhesus monkey (16). Enhancement of small airway branching morphogenesis and surfactant gene expression has been found in embryonic mouse lung culture (23). It is also well known that the incidence of respiratory distress syndrome in premature infants of smoking mothers is reduced due to assumed acceleration of lung maturation in these infants $(20-22)$.

To study distal airway function, we used a multiple-breath nitrogen washout technique, measuring gas-mixing efficiency in the lung. In previous studies, we and others have found that measures of gas-mixing efficiency by means of gas dilution techniques are highly sensitive to changes in the terminal respiratory units of the lung $(41,42)$. The gas mixing of inspired and remaining alveolar gas during breathing is thought to occur in the preacinar and acinar part of the airways by means of a complex interaction between diffusive and convective forces (43). The efficiency of this process is influenced by several factors. According to model studies of gas mixing in terminal respiratory units, the efficiency in this process is highly influenced by airway structure (44). Factors such as alveolar size and number, alveolar septation, and airway branching points all affect the gas-mixing efficiency in the lung. During growth and development, the acinus structure becomes more "complex," facilitating the gas-mixing efficiency during breathing. Factors influencing the normal development of acinus structure also affect gas-mixing efficiency in the lung.

Analysis of gas-mixing efficiency in distal airways showed significantly reduced moment ratio and nitrogen clearance index in the group exposed to a low dose of nicotine compared 
with controls. We interpret these results as an improvement in the ability of the distal airways to mix inspired gas with remaining alveolar gas during breathing. The morphologic structure behind this improvement in gas mixing is not known, inasmuch as we did not examine the structural changes in the lung in this study. One could, however, speculate that the low dose of prenatal nicotine exposure specifically enhanced maturation of the acini in these lambs. An accelerated lung growth (increase in FRC) during the study period in the low-dose nicotine-exposed lambs also speaks in favor of enhanced lung maturation in this group. These results seen in the LN group are in agreement with the clinical findings of accelerated fetal lung maturation in infants of smoking mothers, i.e. earlier appearance of surfactant production (19-21), as well as the findings by Wuenschell et al. (23) in embryonic mouse lung culture showing stimulation of airway branching morphogenesis and increased surfactant gene expression after nicotine exposure. Stimulation of the surfactant-producing cells in the acini (16) in combination with accelerated small airway branching might be the structural background to the improved gas-mixing efficiency found in the low-dose nicotine-exposed lambs. Gas-mixing efficiency in distal airways did not improve in the lambs exposed to a moderate dose of nicotine, indicating that the effect of nicotine on the distal airways might depend on the dose of prenatal exposure.

Our finding of functional evidence of accelerated maturation of the acinar part of the nicotine-exposed lung is in contrast to findings in the rhesus monkey $(16)$ and the rat $(38,39)$ models. In those studies, animals exposed to nicotine prenatally showed morphologic damage and alteration of the normal alveolar structure. The functional consequences of such changes should have been a deterioration of the gas mixing ability in the lung. Besides differences in species susceptibility to nicotine, the most plausible explanation for the discrepancy between our study and those in rhesus monkeys and rats is the difference in the dose of nicotine exposure. The LN lambs in our study were exposed to $0.5 \mathrm{mg} / \mathrm{kg} / \mathrm{d}$ of nicotine, whereas, in the baboon model, the animals were exposed to $1-1.5 \mathrm{mg} / \mathrm{kg} / \mathrm{d}$. In fact, the MN-exposed lambs $(1.5 \mathrm{mg} / \mathrm{kg} / \mathrm{d})$ in our study showed considerably less effective gas mixing on the first study occasion compared with the LN group and less effective mixing in comparison with the control animals (Fig. 3 and 4). Even though this difference in gas mixing between the nicotineexposed groups did not prevail during the whole study period, it might further support the hypothesis that the nicotinic effect on the developing acinus depends on the dose of exposure.

Ventilation and lung volume. In this study, we did not find any significant differences in tidal volume, respiratory rate, or minute ventilation between the nicotine-exposed lambs and the controls on any study occasion. In the MN lambs at $12 \mathrm{~d}$, there was a tendency toward increased minute ventilation, mainly due to an increase in respiratory rate. This difference was, however, not statistically significant. The absence of a difference in breathing pattern between nicotine-exposed and control lambs is in contrast to our previous study in low-dose nicotineexposed lambs, where we found a reduced tidal volume and an increased respiratory rate in comparison with nonexposed lambs (25). However, in that study, the largest effect from prenatal nicotine exposure was seen in lambs studied at an average age of $5 \mathrm{~d}$ instead of $12 \mathrm{~d}$ as in the current study. In the previous study, we found a progressive reduction in the difference in breathing pattern between nicotine-exposed and control lambs after $10 \mathrm{~d}$ of age. Therefore, prenatal nicotine exposure might have its dominating effect on breathing regulation and breathing pattern during the first week after birth, which we could not confirm in our current study because these lambs were not examined until $1 \mathrm{wk}$ later.

The normal FRC found in the nicotine-exposed lambs in this study differs from some previous studies in infants (8) and rats (15) showing a reduction of the lung volume. However, there were differences in FRC gain during the whole study period between the study groups, probably reflecting different lung growth, where LN lambs showed most increase in FRC. We speculate that these differences in FRC gain also might reflect differences in lung maturation between the groups. In comparison with changes in gas-mixing efficiency, however, we found no simple correlation between FRC change and changes in $\mathrm{M}_{1} / \mathrm{M}_{0}$ or $\mathrm{NC}$ over time, indicating that there is no simple relationship between factors influencing lung volume growth and differentiation of peripheral airways.

\section{SUMMARY}

This study showed that prenatal nicotine exposure has complex influences on lung function in young lambs with different effects on proximal and distal airways. The lung mechanics measurements showed signs of airway obstruction in proximal airways, whereas the gas dilution technique showed signs of improved gas mixing in distal airways, which might reflect restriction in large airway growth and accelerated maturation of the acinar part of the lung, respectively. The effect on peripheral airways seemed to be dose related because only the low dose of nicotine improved distal airway function (gasmixing efficiency). However, changes in proximal airway function (specific conductance) seemed to be unrelated to dose. The altered airway function persisted during the whole 51-d-study period, indicating that prenatal nicotine exposure might have a permanent impact on lung development and function with possible long-term health consequences.

Acknowledgments. The authors thank Patricia A. Minton, R.N., Rao Gaddipati, M.S., and Charles A. Dematteo, Jr., for skilled technical assistance, Dr. Neal Benowitz for performing nicotine and cotinine determinations, Dr. Beverly Mellen for performing the randomization procedure, and Dr. James Sheller for his helpful advice.

\section{REFERENCES}

1. Gidding SS, Sehydlouer M 1994 Active and passive tobacco exposure: a serious pediatric health problem. Pediatrics 94:750-751

2. Cliver SP, Goldenberg RL, Cutter GR, Hoffman HJ, Davis RO, Nelson KG 1995 The effect of cigarette smoking on neonatal anthropometric measurements. Obstet Gynecol 85:625-630

3. Steele R, Langworth JT 1966 The relationship of antenatal and postnatal factors to sudden unexpected death in infancy. Can Med Assoc J 94:1165-1171

4. Gergen PJ, Fowler JA, Maurer KR, Davis W, Overpeck MD 1998 The burden of environmental tobacco smoke exposure on the respiratory health of children 2 months through 5 years of age in the United States: Third National Health and Nutrition Examination Survey, 1988 to 1994. Pediatrics 101:e8 
5. Lam TH, Leung GM, Ho LM 2001 The effects of environmental tobacco smoke on health services utilization in the first eighteen months of life. Pediatrics 107:E91

6. Hanrahan JP, Tager IB, Segal MR, Tosteson TD, Castile RG, Van Vunakis H, Weiss ST, Speizer FE 1992 The effect of maternal smoking during pregnancy on early infant lung function. Am Rev Respir Dis 145:1129-1135

7. Tager IB, Hanrahan JP, Tosteson TD, Castile RG, Brown RW, Weiss ST, Speizer FE 1993 Lung function, pre- and post-natal smoke exposure, and wheezing in first year of life. Am Rev Respir Dis 147:811-817

8. Tager IB, Ngo L, Hanrahan JP 1995 Maternal smoking during pregnancy. Effects on lung function during the first 18 months of life. Am J Respir Crit Care Med 152:977-983

9. Brown RW, Hanrahan JP, Castile RG, Tager IB 1995 Effect of maternal smoking during pregnancy on passive respiratory mechanics in early infancy. Pediatr Pulmonol 19:23-28

10. Young S, Le Souef PN, Geelhoed GC, Stick SM, Turner KJ, Landau LI 1991 The influence of a family history of asthma and parental smoking on airway responsiveness in early infancy. N Engl J Med 324:1168-1173

11. Hoo AF, Henschen M, Dezateux C, Costeloe K, Stocks J 1998 Respiratory function among preterm infants whose mothers smoked during pregnancy. Am J Respir Crit Care Med 158:700-705

12. Jones M, Castile R, Davis S, Kisling J, Filbrun D, Flucke R, Goldstein A, Emsley C, Ambrosius W, Tepper R 2000 Forced expiratory flow and volumes in infants. Normative data and lung growth. Am J Respir Crit Care Med 161:353-359

13. Elliot J, Vullermin P, Robinson P 1998 Maternal cigarette smoking is associated with increased inner airway wall thickness in children who die from sudden infant death syndrome. Am J Respir Crit Care Med 158:802-806

14. Elliot J, Vullermin P, Carroll N, James A, Robinson P 1999 Increased airway smooth muscle in sudden infant death syndrome. Am J Respir Crit Care Med 160:313-316

15. Collins MH, Moessinger AC, Kleinerman J, Bassi J, Rosso P, Collins AM, James LS, Blanc WA 1985 Fetal lung hypoplasia associated with maternal smoking: a morphometric analysis. Pediatr Res 19:408-412

16. Sekhon HS, Jia Y, Raab R, Kuryatov A, Pankow JF, Whitsett JA, Lindstrom J, Spindel ER 1999 Prenatal nicotine increases pulmonary alpha-7 nicotinic receptor expression and alters fetal lung development in monkeys. J Clin Invest 103:637-647

17. Sekhon HS, Keller JA, Benowitz NL, Spindel ER 2001 Prenatal nicotine exposure alters pulmonary function in newborn rhesus monkeys. Am J Respir Crit Care Med 164:989-994

18. Elliot J, Carroll N, Bosco M, McCrohan M, Robinson P 2001 Increased airway responsiveness and decreased alveolar attachment points following in utero smoke exposure in the guinea pig. Am J Respir Crit Care Med 163:140-144

19. Sekhon HS, Keller JA, Proskocil BJ, Martin EL, Spindel ER 2002 Maternal nicotine exposure upregulates collagen gene expression in fetal monkey lung. Association with alpha 7 nicotinic acetylcholine receptors. Am J Respir Cell Mol Bio 26:31-41

20. Curet LB, Rao AV, Zachman RD, Morrison J, Burkett G, Poole WK 1983 Maternal smoking and respiratory distress syndrome. Am J Obstet Gynecol 147:446-450

21. White E, Shy KK, Daling JR, Guthrie RD 1986 Maternal smoking and infant respiratory distress syndrome. Obstet Gynecol 67:365-370

22. Lieberman E, Torday J, Barbieri R, Cohen A, Van Vunakis H, Weiss ST 1992 Association of intrauterine cigarette smoke exposure with indices of fetal lung maturation. Obstet Gynecol 79:564-570
23. Wuenschell CW, Zhao J, Tefft JD, Warburton D 1998 Nicotine stimulates branching and expression of SP-A and SP-C mRNAs in embryonic mouse lung culture. Am J Physiol 274:L165-L170

24. Efron B 1971 Forcing a sequential experiment to be balanced. Biometrika 58:403-417

25. Hafström O, Milerad J, Sundell HW 2002 Altered breathing pattern after prenatal nicotine exposure in the young lamb. Am J Respir Crit Care Med 166:92-97

26. Hill P, Haley NJ, Wynder EL 1983 Cigarette smoking: carboxyhemoglobin, plasma nicotine, cotinine and thiocyanate vs self-reported smoking data and cardiovascular disease. J Chronic Dis 36:439-449

27. Jacob III P, Yu L, Wilson M, Benowitz NL 1991 Selected ion monitoring method for determination of nicotine, cotinine, and deuterium-labeled analogs: absence of an isotope effect in the clearance of S-nicotine-3', 3'- $\mathrm{d}_{2}$ in humans. Biological Mass Spectrom 20:247-252

28. Jacob III P, Wilson M, Benowitz NL 1981 Improved gas chromatographic method for the determination of nicotine and cotinine in biologic fluids. J Chromatogr 222:61-70

29. Sandberg K, Edberg KE, Benton W, Silberberg A, Sladek M, Sundell HW 1991 Surfactant improves gas mixing and alveolar ventilation in preterm lambs. Pediatr Res 30:181-189

30. Sandberg K, Sjöqvist BA, Hjalmarson O, Olsson T 1987 Efficiency of ventilation in neonatal pulmonary maladaptation. Acta Paediatr Scand 76:30-36

31. Shao H, Sandberg K, Sjöqvist BA, Hjalmarson O 1998 Moment analysis of multibreath nitrogen washout in healthy preterm infants. Pediat Pulmonol 25:52-58

32. Hjalmarson O 1974 Mechanics of breathing in newborn infants with pulmonary disease. Acta Paediatr Scand 247:5-70

33. Sjöqvist BA, Sandberg K, Hjalmarson O, Olsson T 1986 Method for analysing multiple-breath nitrogen washouts. Med Biol Eng Comput 24:83-90

34. Altman DG 1991 Practical Statistics for Medical Research. Chapman and Hall, London, pp 431-433

35. Macklem PT, Mead J 1967 Resistance of central and peripheral airways measured by a retrograde catheter. J Appl Physiol 22:395-401

36. Macklem PT 1998 The physiology of small airways. Am J Respir Crit Care Med 157:S181-S183

37. Benowitz NL, Kuyt F, Jacob III P, Jones RT, Osman AL 1983 Cotinine disposition and effects. Clin Pharmacol Ther 34:604-611

38. Elliot JG, Carroll NG, James AL, Robinson PJ 2003 Airway alveolar attachment points and exposure to cigarette smoke in utero. Am J Respir Crit Care Med 167:45-49

39. Maritz GS, Woolward KM, du Toit G 1993 Maternal nicotine exposure during pregnancy and development of emphysema-like damage in the offspring. S Afr Med J 83:195-198

40. Maritz GS, Scott L, Thomas RA 1993 The influence of maternal nicotine exposure on neonatal lung alveolar epithelial status: an electron microscope study. Cell Biology Int 17:1085-1089

41. Hjalmarson O, Sandberg K 2002 Abnormal lung function in healthy preterm infants. Am J Respir Crit Care Med 165:83-87

42. Cosio M, Ghezzo H, Hogg JC, Corbin R, Loveland M, Dosman J, Macklem PT 1978 The relations between structural changes in small airways and pulmonary function tests. N Engl J Med 298:1277-1281

43. Paiva M, Engel LA 1987 Theoretical studies of gas mixing and ventilation distribution in the lung. Physiol Rev 67:750-796

44. Engel LA 1983 Gas mixing within the acinus of the lung. J Appl Physiol 54:609-618 